\title{
Tailoring treatment for ductal intraepithelial neoplasia of the breast according to Ki-67 and molecular phenotype
}

\begin{abstract}
M Lazzeroni ${ }^{*}, 1,8$, A Guerrieri-Gonzaga ${ }^{1,8}$, E Botteri $^{2}$, M C Leonardi ${ }^{3}$, N Rotmensz ${ }^{2}$, D Serrano ${ }^{1}$, C Varricchio ${ }^{1}$, D Disalvatore $^{2}$, A Del Castillo ${ }^{4}$, F Bassi ${ }^{4}$, G Pagani ${ }^{4}$, A DeCensi ${ }^{1,5}$, G Viale ${ }^{6,7}$, B Bonanni ${ }^{1}$ and G Pruneri ${ }^{6,7}$

${ }^{1}$ Division of Cancer Prevention and Genetics, European Institute of Oncology, Milan, Italy; ${ }^{2}$ Division of Epidemiology and Biostatistics, European Institute of Oncology, Milan, Italy; ${ }^{3}$ Division of Radiotherapy, Department of Medical Imaging and Radiation Sciences, European Institute of Oncology, Milan, Italy; ${ }^{4}$ Division of Senology, European Institute of Oncology, Milan, Italy; ${ }^{5}$ Division of Medical Oncology, EO Ospedali Galliera, Genoa, Italy; ${ }^{6}$ Division of Pathology, Department of Pathology and Laboratory Medicine, European Institute of Oncology, Milan, Italy and 'University of Milan, School of Medicine, Milan, Italy
\end{abstract}

Background: The post-surgical management of ductal intraepithelial neoplasia (DIN) of the breast is still a dilemma. Ki-67 labelling index (LI) has been proposed as an independent predictive and prognostic factor in early breast cancer.

Methods: The prognostic and predictive roles of Ki-67 LI were evaluated with a multivariable Cox regression model in a cohort of 1171 consecutive patients operated for DIN in a single institution from 1997 to 2007.

Results: Radiotherapy (RT) was protective in subjects with DIN with Ki-67 LI $\geq 14 \%$, whereas no evidence of benefit was seen for $\mathrm{Ki}-67 \mathrm{LI}<14 \%$, irrespective of nuclear grade and presence of necrosis. Notably, the higher the Ki-67 LI, the stronger the effect of RT (P-interaction $<0.01)$. Hormonal therapy $(\mathrm{HT})$ was effective in both Luminal A (adjusted hazard ratio $(\mathrm{HR})=0.56(95 \% \mathrm{Cl}$, 0.33-0.97)) and Luminal B/Her2neg DIN (HR 0.51 (95\% Cl, 0.27-0.95)).

Conclusion: Our data suggest that Ki-67 LI may be a useful prognostic and predictive adjunct in DIN patients. The Ki-67 LI of $14 \%$ could be a potential cutoff for better categorising this population of women at increased risk for breast cancer and in which adjuvant treatment (RT, HT) should be differently addressed, independent of histological grade and presence of necrosis.

The post-surgical management of patients with ductal carcinoma in situ of the breast, recently referred to as ductal intraepithelial neoplasia (DIN1c, 2 and 3; Veronesi et al, 2006) is still a dilemma (Solin, 2012). Following a diagnosis of DIN, the risk of ipsilateral recurrence after breast-conserving surgery (BCS) without radiation therapy (RT) or hormonal therapy (HT) is approximately $30 \%$ at 10 years (Bijker et al, 2006). Four randomised clinical trials have shown that RT after BCS reduced the risk of local recurrence (whether in situ or invasive) by approximately $50 \%$ at 10 and 15 years of follow-up (Fisher et al, 1998; Bijker et al, 2006; Cuzick et al, 2011; Wapnir et al, 2011). In a meta-analysis of 3729 women with DIN, RT after BCS reduced the absolute 10 -year risk of any ipsilateral breast event by $15.2 \%$ (12.9\% with RT vs $28.1 \%$ without RT; $P<0.001$ ) (Correa et al, 2010). Similarly, randomised clinical trials have shown that adding adjuvant tamoxifen reduces the risk of all breast cancer events (ipsilateral plus contralateral) by approximately $30 \%$ at 10 and 15 years of follow-up (Cuzick et al, 2011; Wapnir et al, 2011; Allred et al, 2012). However, neither RT nor HT have been reported to improve survival, and this is particularly relevant when considering that both RT and HT carry rare but serious risks (Paszat et al, 1998, 2007; Cuzick et al, 2011; Wapnir et al, 2011; Allred et al, 2012).

\footnotetext{
*Correspondence: Dr M Lazzeroni; E-mail: matteo.lazzeroni@ieo.it

${ }^{8}$ These two authors contributed equally to this work.
}

Received 5 December 2012; revised 1 March 2013; accepted 7 March 2013; published online 11 April 2013 
As ipsilateral mastectomy is a dearly prize to pay for a minimal or absent risk of recurrence, patients and physicians often opt for conservative surgery followed by RT and HT to reduce the risk of recurrence, despite awareness that this may be an over-treatment for most patients. To improve clinical decision making, Rudloff et al (2010) reported an internally validated nomogram integrating 10 clinical, pathological and treatment-related variables to predict the risk of local recurrence for DIN patients. Unfortunately, a recent report on independent series of patients by Yi et al (2012) did not fully validate this nomogram and again the debate about how to manage at best DIN patients has been re-opened. Both studies (Rudloff et al, 2010; Yi et al, 2012) concur that molecular profiling will potentially improve risk stratification for women with DIN.

Gene expression studies recently led to a better understanding of the biological complexity of invasive breast carcinomas (BCs), allowing to discriminate different molecular subtypes (Luminal A (LumA), Luminal B (LumB), human epidermal growth factor receptor-2 (HER2)-enriched and basal-like) with specific clinical behaviour, whose progression may be tackled using different therapeutic strategies. Interestingly, the application of traditional immunohistochemical markers such as oestrogen receptor (ER), progesterone receptor (PgR), HER2 status and Ki-67 labelling index (LI) has been convincingly demonstrated to be a robust surrogate for the molecular assays in BC classification, and has been therefore recommended in clinical practice and recently endorsed by the San Gallen panellists (Goldhirsch et al, 2011). In particular, Ki-67 LI has been proposed as an independent predictive and prognostic factor in early BC (Urruticoechea et al, 2005), although uncertainty concerning the most effective threshold for discriminating between low and highly proliferative tumours still persists.

To assess the predictive and prognostic power of immunohistochemically defined molecular subtypes and of Ki-67 LI in DIN, we selected a large retrospective series of consecutive patients treated in a single institution over a time frame of $>10$ years.

\section{PATIENTS AND METHODS}

Study population. The study cohort consisted of all consecutive women included in a dedicated institutional database who underwent primary breast surgery at the European Institute of Oncology (EIO) between 1 January 1997 and 31 December 2007, who were diagnosed with DIN1c-3, and who were followed-up by the EIO staff. This is a retrospective study reported in accordance with the REMARK criteria (McShane et al, 2006). Relevant data on patients' medical history, kind of surgery and pathologic assessment of morphologic and biologic features were combined.

Treatment assignment. Treatment assignments have been discussed by a multidisciplinary team on a weekly basis, and overall some differences in treatment selection over the 10-year follow-up period were observed. Whole breast RT was generally not offered to women with low-grade disease (DIN1c). On the other hand, RT was recommended to women with DIN2-DIN3 disease with a combination of risk factors such as young age, the presence of comedo histology or necrosis, and positive margins. Given the results of randomised trials confirming a beneficial effect of RT (Fisher et al, 2001; Bijker et al, 2006), physicians' recommendations towards RT have changed over time. The most common RT schedule was $50 \mathrm{~Gy}$ without a boost. Similarly, preventive drug administration to ER-positive (ERpos) DIN patients has changed during the 11-year period: unless a clinical trial was available, no HT was routinely recommended. However, during the last 5 years, a benefit of low-dose tamoxifen on surrogate end point biomarkers of BC with fewer side effects (Decensi et al, 2007) has been shown in several phase II trials conducted at the EIO in premenopausal women with DIN (Guerrieri-Gonzaga et al, 2006) in healthy women at increased risk for $\mathrm{BC}$ (Decensi et al, 2007), or in the pre-surgical setting of invasive BC (Decensi et al, 2003). Depending on the medical history, low-dose tamoxifen (either $5 \mathrm{mg}$ per day or $20 \mathrm{mg}$ once a week) has been offered to ERpos DIN patients since January 2004. No treatment was administered to women with ER-negative (ERneg) disease (Guerrieri-Gonzaga et al, 2010).

Pathology methods. Our institute adopted the DIN classification since 2006 (Veronesi et al, 2006). The initial version as proposed by Tavassoli (1998) was subsequently modified as follows: DIN 1a: flat epithelial atypia; DIN 1b: atypical ductal hyperplasia (ADH); DIN $1 c$ : DCIS grade 1 (low grade); DIN2: DCIS grade 2 (intermediate grade); DIN3: DCIS grade 3 (high grade). The DIN classification bears in mind that all intraductal proliferations (traditionally subdivided into intraductal hyperplasia without atypia, ADH and DCIS) are in fact a 'continuum'. Furthermore, this classification diminishes the impact of having two different designations of cancer (DCIS) and non-cancer (ADH) applied to the same lesion, caused by interobserver variability (Tavassoli, 2005).

For this analysis, the immunohistochemical data obtained at the time of the original diagnosis without any specific image analysis support have been used. Pathological assessment included evaluation of histological type, grade (Tavassoli, 1998), stage, presence of necrosis and microcalcification. Oestrogen receptor, PgR, Ki-67 LI and HER2 expressions were evaluated by immunohistochemistry, as previously described (Dowsett et al, 2007; Viale et al, 2007; Ellis et al, 2008). For all the probes used, the immunohistochemical results were scored by counting at least 500 cells at $\times 400$ magnification, and by recording the percentage of cells showing any definite nuclear (for ER, PgR and KI-67) and membranous (for HER2) staining. Human epidermal growth factor receptor-2 immunoreactivity assessment was carried out according to the intensity and completeness of cell membrane staining, as per the FDA scoring system (Birner et al, 2001) (HER2pos). The adopted subtype classification based on immunohistochemistry was the following: LumA when either one or both of ER and PgR were present $(\geqslant 1 \%)$, HER2 was not overexpressed and the Ki-67 LI was below < 14\%; LumB when ER and/or PgR were present and Ki-67 LI was $\geqslant 14 \%$ irrespective of HER2 overexpression; HER2pos when ER and PgR were absent and HER2 was overexpressed, irrespective of the Ki-67 LI; triple negative when ER and PgR were absent and HER2 was not overexpressed.

Statistical methods. The main end point was the ipsilateral breast recurrence, whether in situ or invasive. Its cumulative incidence was calculated from surgery to the ipsilateral breast recurrence as first event or to last visit in case of no events. Other first events such as contralateral recurrences, other primary tumours and deaths were considered as competing events. The Gray test was used to test the difference in the cumulative incidence between subgroups of patients. A multivariate Cox proportional hazards regression model was used to evaluate the independent effect of the factors, which were statistically significant at the univariate analysis. Tumour grade was also added in the multivariable analyses when evaluating the independent effect of Ki-67 LI, molecular subtype and treatment. To evaluate the effect of RT, patients with DIN2-DIN3 undergoing BCS were selected, whereas patients with ERpos DIN were investigated for the role of HT. To examine the shape of the relationship between Ki-67 LI and the hazard of local recurrence, a multivariable restricted cubic spline model was used (Durrleman and Simon, 1989). Cubic splines are smoothly joined piecewise third-order polynomials. Polynomials are fitted within intervals delimited by knots, and restrictions are placed on the resulting curve to ensure a smooth appearance at the knot points. A four-knot analysis was performed. A multivariable fractional polynomial interaction (MFPI) model was used to detect an interaction between the effect of RT and Ki-67 LI on the risk of local recurrence (Royston and Sauerbrei, 2004). All multivariable 
analyses were adjusted for clinical, pathological prognostic features and treatments, as appropriate. All analyses were carried out with the SAS software (SAS Institute, Cary, NC, USA) and the R (http://cran.r-project.org/) software with the Harrell's Design and Hmisc libraries. STATA Statistical Software (StataCorp LP, College Station, TX, USA) was used to estimate the MFPI model. All the reported $P$-values were two sided.

\section{RESULTS}

From January 1997 to December 2007, a total of 1171 female patients with DIN were referred to the interdisciplinary evaluation, and their data were included in the institutional database. Table 1 summarises the main baseline characteristics of the entire cohort. Mastectomy $(n=299)$ was more frequent in young women $(35.4 \%$ in women $<50$ years and $18.4 \%$ in women $\geqslant 50$ years; $P<0.01$ ). Overall, the number of women with DIN2-DIN3 disease not receiving RT decreased from $65.6 \%$ in the years 1997-2002 to $56.5 \%$ in the years $2002-2004$ to $37.8 \%$ in the years $2005-2007$. In all, 19 of 224 (8.5\%) women with DIN1c received RT. Preventive systemic treatment included any active pharmacological treatment: 441 of $506(87.2 \%)$ patients treated with preventive HT received low-dose tamoxifen (either $5 \mathrm{mg}$ per day or $20 \mathrm{mg}$ once a week) for up to 5 years. Sixty-five patients were given other preventive drugs, including the retinoid fenretinide ( $200 \mathrm{mg}$ per day) or tamoxifen standard dose $(20 \mathrm{mg}$ per day) or the aromatase inhibitor anastrozole ( $1 \mathrm{mg}$ per day) as part of phase II clinical trials. Notably, at univariate analysis, factors significantly associated with ipsilateral recurrence $(P \leqslant 0.05)$ were age and menopausal status, microcalcifications, necrosis, Ki-67 LI, type of surgery, HT and RT (Table 1). On multivariable analysis, all these factors remained statistically significant but the presence of necrosis. After a median follow-up of 86 months (range, 1-192 months), a total of 215 breast events occurred, including 79 local in situ, 84 invasive (64 local, 20 loco-regional) and 52 contralateral (15 in situ and 37 invasive) events. Thirty-one deaths were observed (5 for BC, 14 for other tumours, 7 for other causes and 5 for unknown reasons). Only 57 women (4.9\%) had no information for the last 2 years.

When patients were stratified by Ki-67 LI $(<14 \%(n=538$, $46 \%)$, between $14 \%$ and $20 \%(n=272,23.2 \%)$, and $>20 \%$ $(n=361,30.8 \%))$ ipsilateral recurrences (5-year cumulative incidence) were 66 (9.4\%), 39 (10.3\%) and 58 (13.0\%), respectively (Wilcoxon test for trend $P=0.05$ ). When analysing Ki-67 LI as a continuous variable, the risk of recurrence increased steeply with increasing Ki-67 LI up to about 14\%, then less steeply for values up to $30 \%$, and remained approximately flat after $30 \%$ (Figure 1 ). The prognostic role of $\mathrm{Ki}-67$ on the risk of local recurrence was statistically significant $(P=0.02)$, after the adjustment for the clinical factors shown to be predictive of recurrence, including treatments and tumour grade. When patients were stratified according to the LumA, LumB/HER2neg and LumB/HER2pos types, the 5-year cumulative incidence of ipsilateral recurrence was $9.1 \%, 10.3 \%$ and $15.3 \%$, respectively, with an adjusted hazard ratios (HRs) LumBHER2neg $v s$ LumA of 1.58 (95\% CI, 1.01-2.47) and $\mathrm{HR}_{\text {LumBHER2pos vs LumA }}$ of 1.70 (95\% CI, 1.05-2.75; Figure 2A). Both HRs were adjusted for the clinical factors shown to be predictive of recurrence, including treatments and tumour grade. No difference in the 5-year cumulative incidence in the HER2pos and triple-negative subgroups was observed (Figure 2B).

The role of low-dose tamoxifen according to subtypes in patients with ERpos DIN is shown in Figure 3. Low-dose tamoxifen was significantly effective in both LumA (adjusted $\mathrm{HR}_{\mathrm{HT} \text { vs NoHT}}$ : 0.56 (95\% CI, 0.33-0.97)) and LumB/HER2neg DIN $\left(\mathrm{HR}_{\mathrm{HT}}\right.$ vs NoHT: 0.51 (95\% CI, 0.27-0.95)), but not in LumB/ HER2pos $\left(\mathrm{HR}_{\mathrm{HT} \text { vs NoHT: }} 1.06\right.$ (95\% CI, 0.56-2.05). Notably, the

\begin{tabular}{|c|c|c|c|}
\hline & Total & $\begin{array}{c}\text { Ipsilateral } \\
\text { recurrences } \\
(5 \text {-year } \\
\text { cumulative } \\
\text { incidence \%) }\end{array}$ & $\boldsymbol{P}$-value \\
\hline All patients & 1171 & $163(10.7)$ & \\
\hline \multicolumn{4}{|l|}{ Age (years) } \\
\hline $\begin{array}{l}\leqslant 39 \\
40-49 \\
50-64 \\
\geqslant 65\end{array}$ & $\begin{array}{c}61(5.2) \\
431(36.8) \\
479(40.9) \\
200(17.1)\end{array}$ & $\begin{array}{l}20(28.5) \\
65(12.3) \\
57(8.0) \\
21(8.4)\end{array}$ & $<0.01$ \\
\hline \multicolumn{4}{|l|}{ Menopause } \\
\hline $\begin{array}{l}\text { Pre } \\
\text { Post }\end{array}$ & $\begin{array}{l}549(46.9) \\
622(53.1)\end{array}$ & $\begin{array}{l}93(13.3) \\
70(8.4)\end{array}$ & $<0.01$ \\
\hline \multicolumn{4}{|l|}{$\mathrm{BMI}^{\mathrm{a}}\left(\mathrm{kg} \mathrm{m}^{-2}\right)$} \\
\hline $\begin{array}{l}<18.5 \\
18.5-24.9 \\
25-29.9 \\
\geqslant 30\end{array}$ & $\begin{array}{c}51(4.6) \\
743(66.4) \\
244(21.8) \\
81(7.2)\end{array}$ & $\begin{array}{c}9(16.8) \\
110(10.6) \\
26(8.9) \\
10(12.9)\end{array}$ & 0.30 \\
\hline \multicolumn{4}{|c|}{ Main histotype } \\
\hline $\begin{array}{l}\text { Comedo } \\
\text { Solid } \\
\text { Micropapillar } \\
\text { Cribriform } \\
\text { Hypersecretory } \\
\text { Apocrine }\end{array}$ & $\begin{array}{c}91(7.8) \\
451(38.5) \\
162(13.8) \\
430(36.7) \\
5(0.4) \\
32(2.7)\end{array}$ & $\begin{array}{l}15(15.2) \\
57(8.4) \\
29(14.5) \\
57(10.7) \\
2(40.0) \\
3(6.4)\end{array}$ & 0.25 \\
\hline \multicolumn{4}{|c|}{ Distance from tumour to surgical margins $(\mathrm{mm})$} \\
\hline $\begin{array}{l}>0 \text { and }<1 \\
\geqslant 1 \text { and }<10 \\
\geqslant 10\end{array}$ & $\begin{array}{l}148(12.7) \\
141(12.0) \\
882(75.3)\end{array}$ & $\begin{array}{c}20(10.5) \\
27(16.1) \\
116(9.8)\end{array}$ & 0.17 \\
\hline \multicolumn{4}{|c|}{ Microcalcifications $^{a}$} \\
\hline $\begin{array}{l}\text { Absent } \\
\text { Present }\end{array}$ & $\begin{array}{l}290(24.9) \\
875(75.1)\end{array}$ & $\begin{array}{c}56(16.2) \\
107(9.0)\end{array}$ & $<0.01$ \\
\hline \multicolumn{4}{|l|}{ Necrosis $^{a}$} \\
\hline $\begin{array}{l}\text { Absent } \\
\text { Present }\end{array}$ & $\begin{array}{l}485(41.5) \\
683(58.5)\end{array}$ & $\begin{array}{l}82(13.4) \\
81(8.9)\end{array}$ & 0.02 \\
\hline \multicolumn{4}{|l|}{ Grade } \\
\hline $\begin{array}{l}\text { DIN1 } \\
\text { DIN2 } \\
\text { DIN3 }\end{array}$ & $\begin{array}{l}224(19.1) \\
619(52.9) \\
328(28.0)\end{array}$ & $\begin{array}{l}28(9.1) \\
90(10.4) \\
45(12.4)\end{array}$ & 0.66 \\
\hline \multicolumn{4}{|l|}{ ER (\%) } \\
\hline $\begin{array}{l}0 \\
1-49 \\
50-100\end{array}$ & $\begin{array}{c}230(19.6) \\
89(7.6) \\
852(72.8)\end{array}$ & $\begin{array}{r}25 \text { (9.8) } \\
17(14.7) \\
121(10.5)\end{array}$ & 0.28 \\
\hline \multicolumn{4}{|l|}{$\mathrm{PgR}(\%)$} \\
\hline $\begin{array}{l}0 \\
1-49 \\
50-100\end{array}$ & $\begin{array}{l}360(30.7) \\
348(29.7) \\
463(39.5)\end{array}$ & $\begin{array}{l}43(9.7) \\
52(11.9) \\
68(10.5)\end{array}$ & 0.39 \\
\hline \multicolumn{4}{|l|}{ Ki-67 LI (\%) } \\
\hline $\begin{array}{l}<14 \\
14-20 \\
>20\end{array}$ & $\begin{array}{l}538(45.9) \\
272(23.2) \\
361(30.8)\end{array}$ & $\begin{array}{l}66(9.4) \\
39(10.3) \\
58(13.0)\end{array}$ & 0.05 \\
\hline
\end{tabular}




\begin{tabular}{|c|c|c|c|}
\hline & Total & $\begin{array}{l}\text { Ipsilateral } \\
\text { recurrences } \\
\text { (5-year } \\
\text { cumulative } \\
\text { incidence \%) }\end{array}$ & $\boldsymbol{P}$-value \\
\hline \multicolumn{4}{|c|}{ HER2/neu overexpression } \\
\hline $\begin{array}{l}\text { Absent } \\
\text { Present }\end{array}$ & $\begin{array}{l}773(66.0) \\
398(34.0)\end{array}$ & $\begin{array}{l}105(9.6) \\
58(12.9)\end{array}$ & 0.67 \\
\hline \multicolumn{4}{|l|}{ Molecular subtype } \\
\hline $\begin{array}{l}\text { Luminal A } \\
\text { Luminal B } \\
\text { (HER2neg) } \\
\text { Luminal B (HER2pos) } \\
\text { HER2 } \\
\text { Triple negative }\end{array}$ & $\begin{array}{l}463(39.5) \\
267(22.8) \\
213(18.2) \\
185(15.8) \\
43(3.7)\end{array}$ & $\begin{array}{l}56(9.1) \\
44(10.3) \\
38(15.3) \\
20(10.0) \\
5(9.8)\end{array}$ & 0.20 \\
\hline \multicolumn{4}{|l|}{ Surgery } \\
\hline $\begin{array}{l}\text { BCS } \\
\text { Mastectomy }\end{array}$ & $\begin{array}{l}872(74.5) \\
299(25.5)\end{array}$ & $\begin{array}{c}142(12.4) \\
21(5.6)\end{array}$ & $<0.01$ \\
\hline \multicolumn{4}{|c|}{ Hormonal treatment ERpos only } \\
\hline $\begin{array}{l}\text { Yes } \\
\text { No }\end{array}$ & $\begin{array}{l}506(53.7) \\
435(46.3)\end{array}$ & $\begin{array}{l}62(9.8) \\
76(12.2)\end{array}$ & 0.05 \\
\hline \multicolumn{4}{|c|}{ Radiotherapy BCS only } \\
\hline Yes & $356(40.8)$ & $37(8.5)$ & $<0.01$ \\
\hline No & $516(59.2)$ & $105(15.1)$ & \\
\hline \multicolumn{4}{|c|}{ 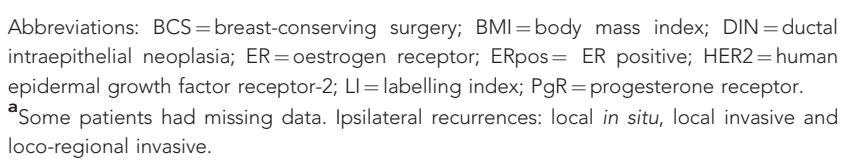 } \\
\hline
\end{tabular}

effect of low-dose tamoxifen was significantly different according to HER2 status (LumA and LumB/HER2neg vs LumB/HER2pos interaction $P$-value: 0.047). Highly hormone-responsive HER2pos DIN (ER and $\mathrm{PgR} \geqslant 50 \%$ ) had a non-statistically significant benefit from the treatment $\left(\mathrm{HR}_{\mathrm{HT}}\right.$ vs NoHT: 0.47 (95\% CI, 0.12-1.78); interaction $P$-value: 0.498 ) (Figure 4). This evidence was obtained in a small subset of 55 patients, not allowing to draw any definitive conclusion. Patients with low-expression of ER or PgR did not benefit from low-dose tamoxifen. Overall, patients with highly positive ER and PgR ( $\geqslant 50 \%)$ DIN who did not receive tamoxifen $(n=203)$ had a significantly higher cumulative incidence of ipsilateral recurrence at 5 years compared with patients with ER and $\mathrm{PgR}<50 \%$ DIN ( $14.6 \%$ vs $10.4 \%$ respectively, Gray test $P$ value 0.050 ). When we analysed the subgroup of 294 luminal DIN patients who did not receive RT or HT ( $n=176 \mathrm{LumA}, 61 \mathrm{LumB} /$ HER2neg and 57 LumB/HER2pos), the adjusted HR were 2.38 (95\% CI, 1.25-4.51) and 1.75 (95\% CI, 0.84-3.61) for LumB/ HER2neg vs LumA and LumB/HER2pos vs LumA, respectively (data not shown).

We analysed the role of $\mathrm{RT}$ according to $\mathrm{Ki}-67 \mathrm{LI}$ as a continuous variable in DIN2/DIN3 patients after BCS. Curve and interaction model were adjusted for menopause, body mass index, HER2, ER, grade, presence of necrosis, margins and microcalcifications, and HT. Radiation therapy was protective in patients with DIN with $\mathrm{Ki}-67 \mathrm{LI} \geqslant 14 \%$, whereas no evidence of protection was seen for Ki-67 LI $<14 \%$. Notably, the higher the Ki-67 LI, the stronger the effect of RT ( $P$-value for interaction between RT and Ki-67 LI $<0.01$; Figure 5).

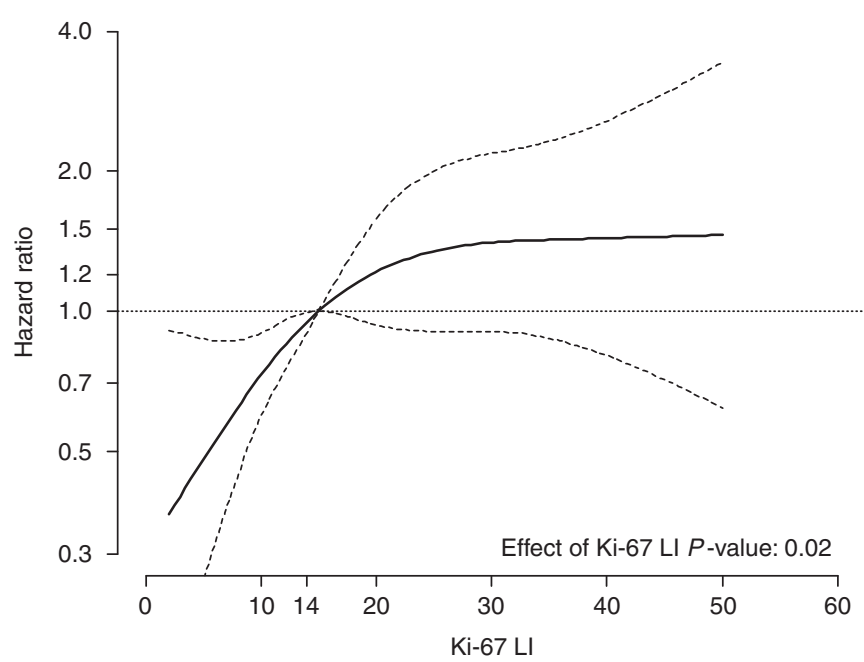

Figure 1. The solid curve represents the continuous relationship between $\mathrm{Ki}-67 \mathrm{LI}$ and the risk of ipsilateral recurrence. The underlying model is adjusted for menopause, body mass index, surgical margins, HER2, ER, grade, presence of necrosis and microcalcifications, type of surgery, RT and HT. Dotted curves represent $95 \% \mathrm{Cls}$. $\mathrm{Ki}-67 \mathrm{LI}$ of $14 \%$ is chosen as the reference value $(H R=1)$.

Radiation therapy was effective in all the subtypes of DIN but LumA subtype, where no benefit was observed. As shown in Figure 6, the adjusted $\mathrm{HR}_{\mathrm{RT}}$ vs NoRT for LumB/HER2neg, LumB/ HER2pos and HER2pos subtypes was 0.20 (95\% CI, 0.08-0.48), 0.44 (95\% CI, $0.16-1.20)$ and 0.15 (95\% CI, 0.04-0.50), respectively. The HR for triple-negative subtype was 0.40 (95\% CI, 0.07-2.41) and was not adjusted because of the sparse number of events.

Finally, to investigate the effect of RT according to histological grade, we focused the analysis on DIN2 patients stratified by Ki-67 LI. After adjustment for menopause, surgical margins, presence of necrosis, microcalcifications and HT, RT was not effective in DIN2 patients showing a Ki-67 LI <14\% $\left(\mathrm{HR}_{\mathrm{RT}}\right.$ s $\mathrm{NoRT}$ : 1.15 (95\% CI, $0.47-2.80)$ ). On the contrary, DIN2 with Ki-67 LI $\geqslant 14 \%$ benefit the most from $\mathrm{RT}$ in terms of ipsilateral recurrence $\left(\mathrm{HR}_{\mathrm{RT}}\right.$ vs NoRT: 0.18 (0.07-0.46); Figure 7).

\section{DISCUSSION}

Although the results are not extrapolated from a randomised clinical trial, and may contain different selection biases, we believe our data provide some important hints to be further investigated in a large phase III trial. Younger age at diagnosis and high-grade DIN have been associated with an increased risk of local recurrence (Fisher et al, 1999; Vicini et al, 2000; Kerlikowske et al, 2003; Boughey et al, 2007), although these factors do not distinguish the individual's risk of developing in situ or invasive recurrences. Despite several studies evaluated the prognostic significance of ER, PgR and HER2 status as predictors in DIN (Ringberg et al, 2001; Provenzano et al, 2003; Cornfield et al, 2004; Kerlikowske et al, 2010), the relevance of Ki-67 LI has been relatively less investigated so far. In our study, we evaluated the clinical outcomes and relationships between $\mathrm{Ki}-67 \mathrm{LI}$ and prognosis in a large cohort of patients with DIN of the breast. We demonstrated that the risk of recurrence for DIN increased steeply with increasing Ki-67 LI up to about $14 \%$, then less steeply up to $30 \%$ and remained approximately flat after $30 \%$, suggesting a potential cutoff for better categorising this population of women at increased risk for 
A

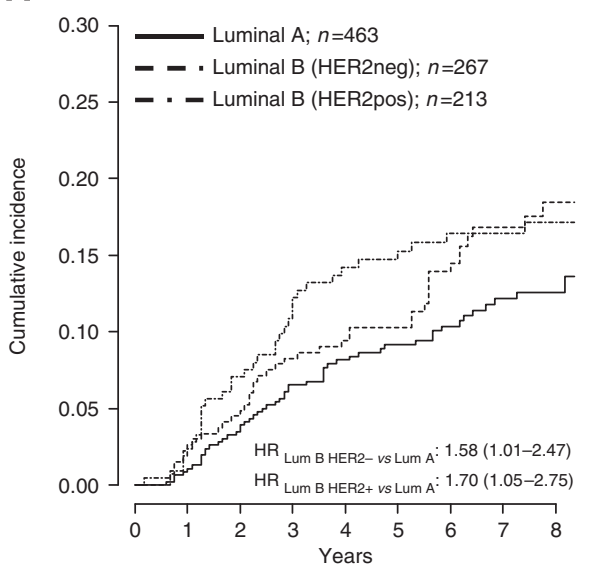

\section{B}

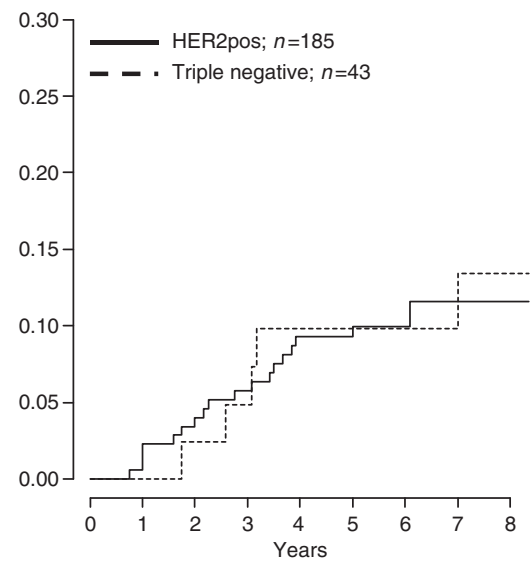

Figure 2. Hazard ratios are adjusted for menopause, body mass index, surgical margins, grade, presence of necrosis and microcalcifications, type of surgery, RT and HT. A: Luminal; B: Non-luminal.
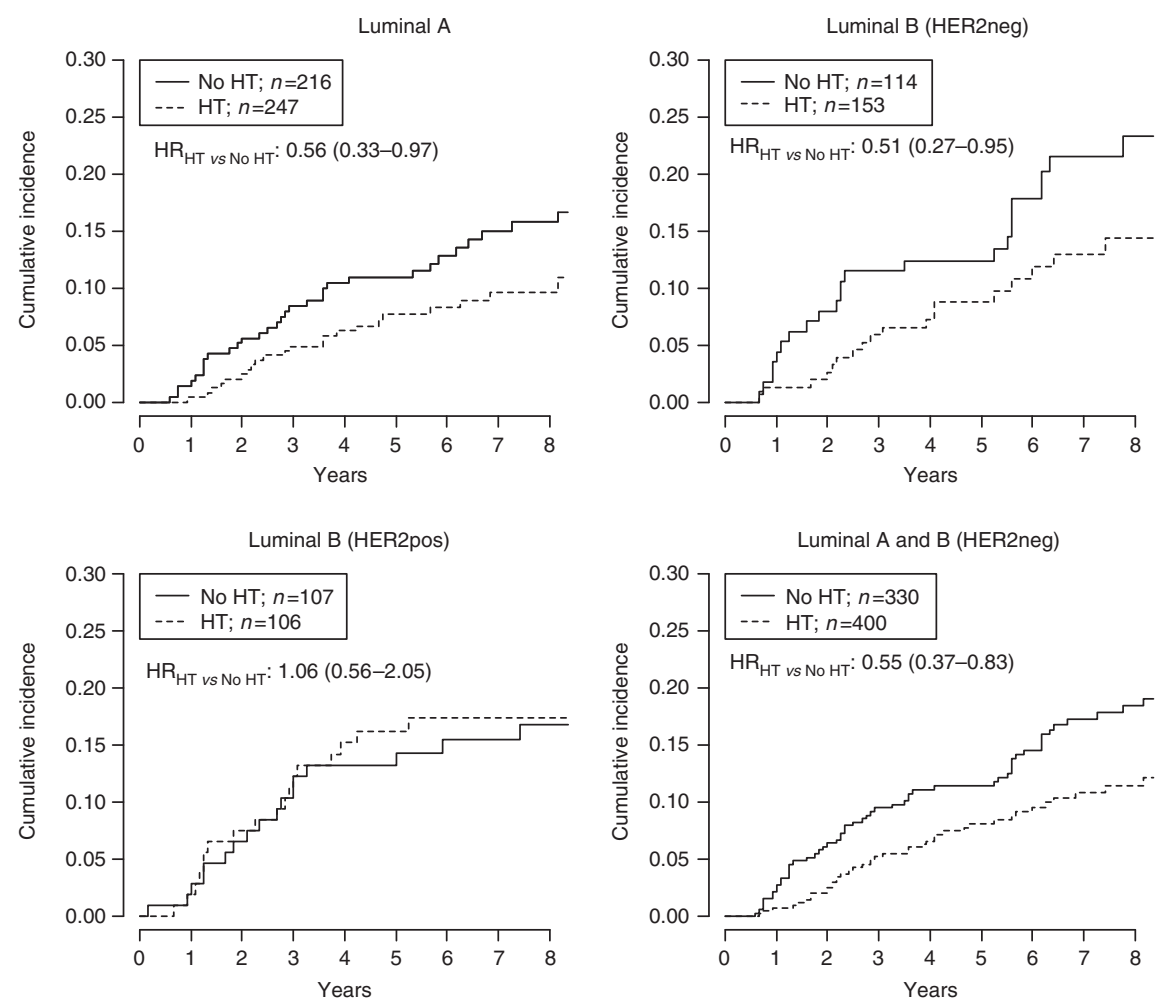

Figure 3. All HRs are adjusted for menopause, body mass index, surgical margins, grade, presence of necrosis and microcalcifications, type of surgery and RT.

BC and in which preventive RT should be differently addressed, independently of histological grade. Notably, the extrapolated Ki-67 LI cutoff coincides with that identified by Cheang et al (2009) for the subtype classification of invasive BC. Although the translation of large-scale genomic analyses of DIN into clinically applicable predictive biomarkers are awaited, the study by Cheang et al (2009) demonstrated that expression of ER, PgR, HER2 and the Ki-67 LI appear to distinguish LumA from LumB BC subtypes. In particular, the best $\mathrm{Ki}-67 \mathrm{LI}$ cut point to distinguish LumB from LumA tumours was $13.25 \%$.

Interestingly, our findings corroborate the results of two previous studies (Kerlikowske et al, 2010; Rakovitch et al, 2012) of population-based cohorts in which individuals with DIN had been treated by BCS alone or followed by RT, which showed a prognostic role of high Ki-67 ( $>10 \%$ ) when associated to other biomarkers.

In our institution, the indication for RT after BCS for DIN is the presence of necrosis and/or high tumour grade (G3). However, 59 women with Ki-67 LI $<14 \%$ received RT after surgery for a LumA DIN (because of young age or margin involvement), without any reduction of the risk of recurrence. According to our results, women with LumA DIN with Ki-67 LI $<14 \%$ could be spared RT. Patients with all the other DIN subtypes who received RT had a significant protection in terms of ipsilateral recurrence compared with those who did not, and the effect was independent of tumour grade, presence of necrosis and HT. Although our results should be considered with caution in the absence of randomisation, the adjustment in the multivariable analysis should provide a reliable 

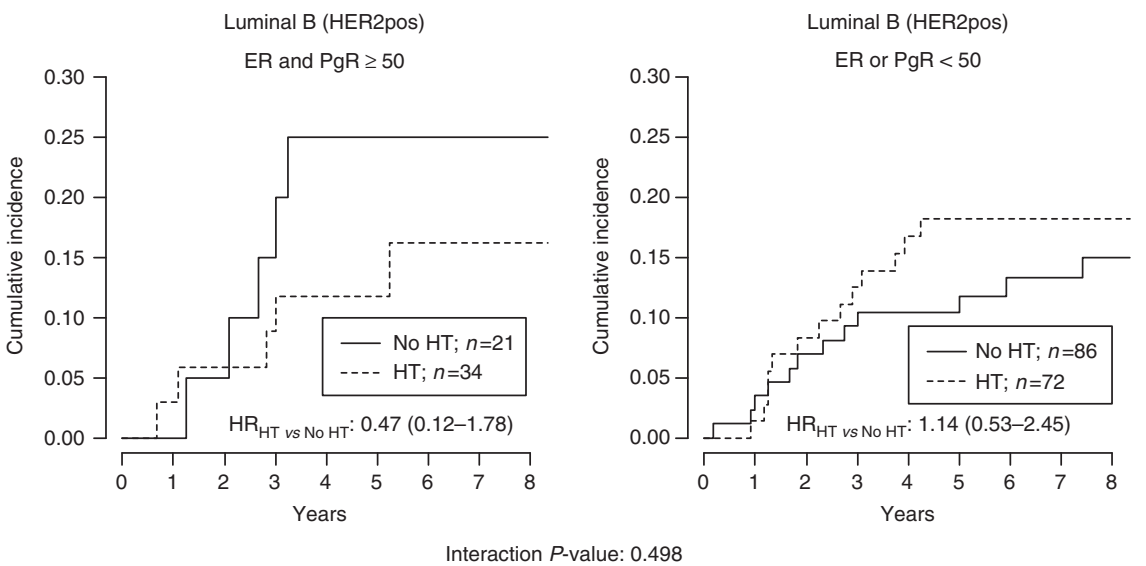

Figure 4. Hazard ratios were adjusted for type of surgery and RT.

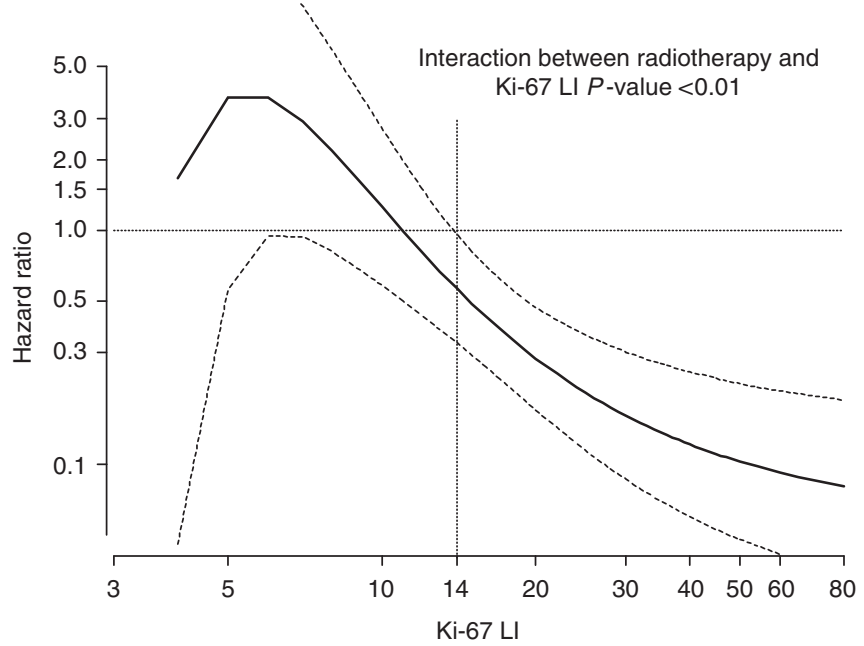

Figure 5. The solid curve represents the continuous relationship between $\mathrm{Ki}-67 \mathrm{LI}$ and the effect of radiotherapy on the occurrence of ipsilateral recurrence. $H R=1$ : no effect of $R T$. $H R<1$ : protective effect of RT. The underlying model is adjusted for menopause, body mass index, surgical margins, HER2, ER, grade, presence of necrosis and microcalcifications and HT. Dotted lines represent the $95 \% \mathrm{Cls}$. Ki-67 LI is reported in a log scale.

estimate of the effect of RT. All patients with DIN3 and DIN2 with a Ki-67 LI $\geqslant 14 \%$, should receive RT irrespective of the occurrence of necrosis.

Oestrogen receptor and $\mathrm{PgR}$ expression are established predictive factors for clinical response to endocrine treatment, but the prognostic significance of their expression level remains an intriguing matter of debate. A recent meta-analysis reported a limited evidence that women whose DIN is ERneg, PR-negative or HER2/neu receptor positive have an higher risk of recurrence than those whose DIN is ERpos, PR-positive and HER2/neu receptor negative (Wang et al, 2011). However, a different perspective emerged from a study in the early 1990s in invasive disease using a graduated scale of receptor expression by biochemistry. Analysing 952 postmenopausal women with untreated breast cancer, those with the highest ER levels had, in fact, as poor a prognosis as ERneg patients, whereas those with intermediate ER levels had the longest recurrence-free survival (Thorpe et al, 1993). In our analysis, the cut point between the ER and PgR expression levels used to define high endocrine responsiveness was $50 \%$ of positive tumour cells, according to the St Gallen International Expert Consensus on the Primary Therapy of Early Breast Cancer 2009
(Goldhirsch et al, 2009). We confirmed our previous results (Guerrieri-Gonzaga et al, 2010) in which high ER and especially high PgR expression ( $>50 \%$ ) was a significant adverse prognostic indicator of DIN. Although our findings should be viewed with caution as they derive from a non-randomised comparison, lowdose tamoxifen was effective in patients with highly endocrineresponsive DIN, and it should be recommended as a post-surgical treatment for women with DIN characterised by Ki-67 LI $<14 \%$, ER $>50 \%, \operatorname{PgR}>50 \%$ if no contraindication occur. On the contrary, DIN patients with lower expression of steroid hormone receptors (in particular $\mathrm{PgR}<50 \%$ ) did not benefit from low-dose tamoxifen and may remain untreated or participate in clinical trials to test different compounds. A possible explanation might be that PgR expression is promoted by ER and may thus identify a subgroup of DIN with a less activated ER pathway with the lower sensitivity to endogenous hormones (Decensi et al, 2012). Studies have found HER2 to be of prognostic significance in invasive cancer; however, its importance in DIN has yet to be elucidated (Latta et al, 2002; Lari and Kuerer, 2011). In the adjuvant setting, HER-2 overexpression has been associated with a poor prognosis and may predict resistance to tamoxifen (Osborne et al, 2003; De Placido et al, 2003). In our series, low-dose tamoxifen seems to be neither effective nor detrimental in DIN-overexpressing HER2. With regard to $\mathrm{HT}, 20 \mathrm{mg}$ per day tamoxifen is a common treatment for ERpos DIN, although the results from randomised clinical trials are not conclusive (Houghton et al, 2003; Cuzick et al, 2011; Wapnir et al, 2011; Allred et al, 2012). Other drugs such as aromatase inhibitors are currently under investigation in two large international phase III trials in postmenopausal women with ERpos DIN, comparing $20 \mathrm{mg}$ per day tamoxifen with $1 \mathrm{mg}$ per day anastrozole (Cuzick, 2003; NSABP-B-35, 2012). However, data from the adjuvant setting with anastrozole have shown some toxicity (Baum et al, 2003) that needs to be taken into account when treating less aggressive disease, such as non-invasive BC. In spite of the long half-life of tamoxifen (Buckley and Goa, 1989) and its active metabolites, the strategy of lowering the standard dose of this drug has not yet been evaluated in DIN patients. Although limited by the lack of a randomised comparison, our results suggest that the promising beneficial effect on surrogate biomarkers observed in phase II trials (Decensi et al, 2007) now has clinical confirmation as a potentially effective risk reduction approach. A randomised placebo-controlled phase III trial for women with DIN or LIN is currently underway and will provide additional information about the efficacy and safety of $5 \mathrm{mg}$ per day of tamoxifen in the preventive setting (Zanardi et al, 2011).

The variability of Ki-67 LI determination across pathology labs is now a major concern, especially if a precise cutoff is proposed to discriminate DIN patients who should undergo RT. To address this 

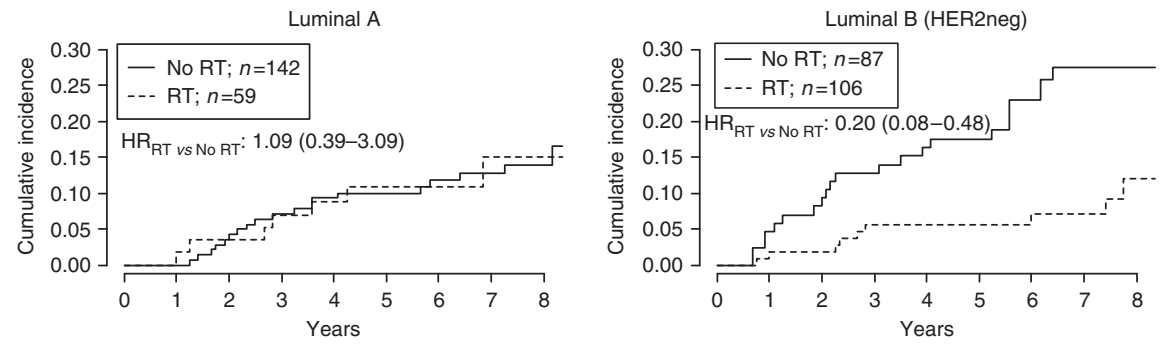

Luminal B (HER2pos)
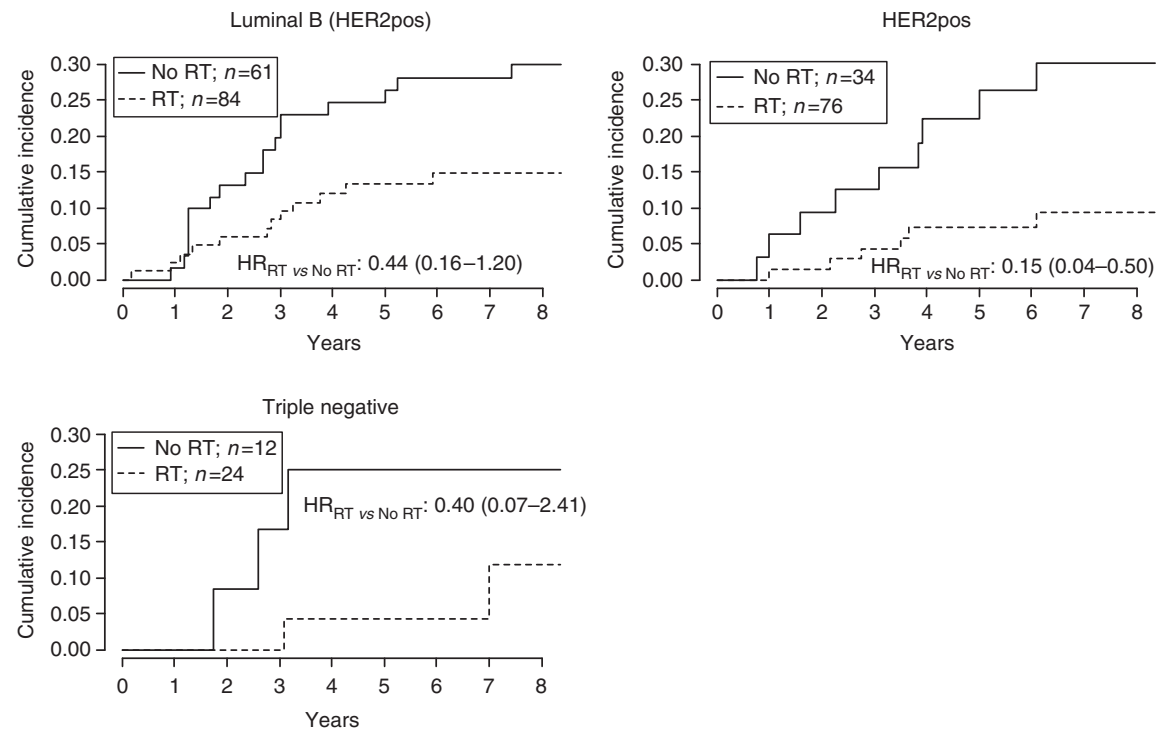

Figure 6. HRs for all subtypes but triple negative were adjusted for menopause, body mass index, surgical margins, grade, presence of necrosis and microcalcifications and HT. HR for triple negative tumours was unadjusted because of the sparse number of events.
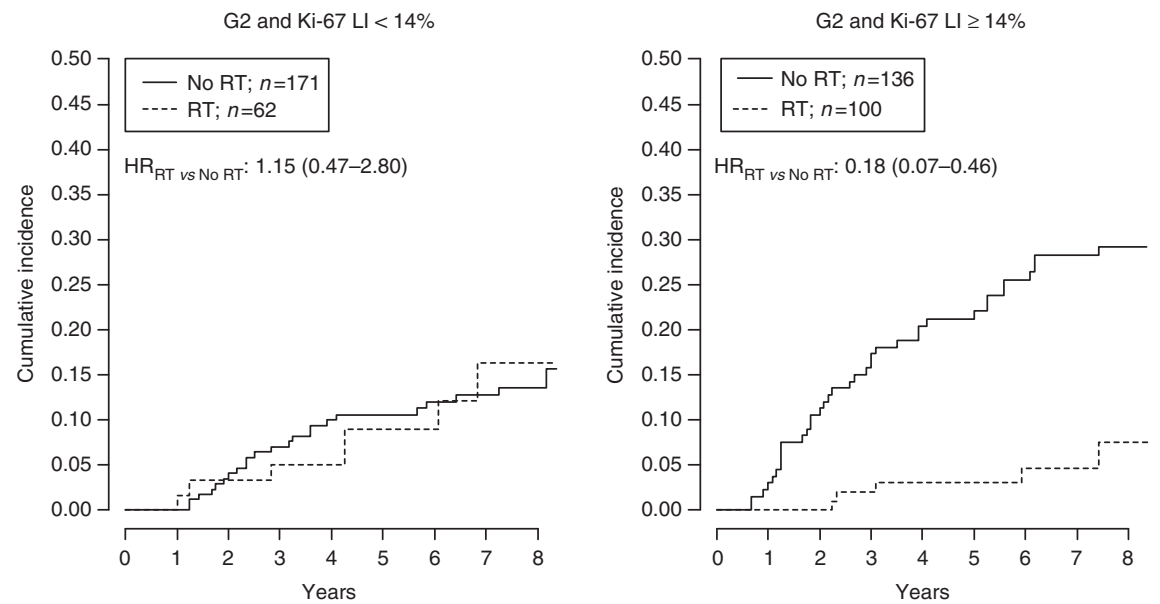

Figure 7. Hazard ratios were adjusted for menopause, surgical margins, presence of necrosis and microcalcifications and HT.

issue, the International Ki67 in Breast Cancer Working Group has recently released guidelines, based on current evidence, that should allow harmonisation of methodology and lead to the definition of the clinical utility of this potentially important marker (Dowsett et al, 2011). Ki-67 LI, as assessed by IHC with the monoclonal antibody MIB1, has the largest body of literature support. The panellists endorsed $\mathrm{Ki}-67 \mathrm{LI}$ as one of the most robust immunohistochemical biomarkers, showing relatively consistent measurements in specimens across a range of conditions used in routine fixation, tissue processing, and IHC analysis (Dowsett et al, 2011). In conclusion, more research is needed to determine whether prognostic factors, useful biomarkers and/or more complex molecular signatures will contribute to develop innovative classifications able to reflect the clinical behaviour of DIN subtype and consequently guide treatment choices.

The molecular alterations associated with local in situ recurrence differ from those associated with invasive recurrence (Rakovitch et al, 2012). Further research is needed to identify biomarkers distinguishing individuals at risk for in situ recurrences from those at risk of developing invasive recurrences, to further evaluate the prognostic role of Ki-67 LI alone or in combination with other biomarkers on the risk of in situ and invasive recurrence, and to validate the effects of RT on the clinical outcomes of the disease. 


\section{ACKNOWLEDGEMENTS}

We thank Margherita Omesso for writing assistance. This work was supported by the Italian Foundation for Cancer Research; a regional grant no. 1068 on second tumours from the Associazione Italiana per la Ricerca sul Cancro (AIRC 36/08); Italian League Against Cancer (LILT 07/08); Italian Ministry of Health (RPFS-2006-1-339898).

\section{REFERENCES}

Allred DC, Anderson SJ, Paik S, Wickerham DL, Nagtegaal ID, Swain SM, Mamounas EP, Julian TB, Geyer Jr CE, Costantino JP, Land SR, Wolmark N (2012) Adjuvant tamoxifen reduces subsequent breast cancer in women with estrogen receptor-positive ductal carcinoma in situ: a study based on NSABP protocol B-24. J Clin Oncol 30: 1268-1273.

Baum M, Buzdar A, Cuzick J, Forbes J, Houghton J, Howell A, Sahmoud T. The ATAC (Arimidex TaoiCTG) (2003) Anastrozole alone or in combination with tamoxifen versus tamoxifen alone for adjuvant treatment of postmenopausal women with early-stage breast cancer: results of the ATAC (arimidex, tamoxifen alone or in combination) trial efficacy and safety update analyses. Cancer 98: 1802-1810.

Bijker N, Meijnen P, Peterse JL, Bogaerts J, Van H I, Julien JP, Gennaro M, Rouanet P, Avril A, Fentiman IS, Bartelink H, Rutgers EJ (2006) Breast-conserving treatment with or without radiotherapy in ductal carcinoma-in-situ: ten-year results of European Organisation for Research and Treatment of Cancer randomized phase III trial 10853-a study by the EORTC Breast Cancer Cooperative Group and EORTC Radiotherapy Group. J Clin Oncol 24: 3381-3387.

Birner P, Oberhuber G, Stani J, Reithofer C, Samonigg H, Hausmaninger H, Kubista E, Kwasny W, Kandioler-Eckersberger D, Gnant M, Jakesz R (2001) Evaluation of the United States Food and Drug Administrationapproved scoring and test system of HER-2 protein expression in breast cancer. Clin Cancer Res 7: 1669-1675.

Boughey JC, Gonzalez RJ, Bonner E, Kuerer HM (2007) Current treatment and clinical trial developments for ductal carcinoma in situ of the breast. Oncologist 12: 1276-1287.

Buckley MM, Goa KL (1989) Tamoxifen. A reappraisal of its pharmacodynamic and pharmacokinetic properties, and therapeutic use. Drugs 37: 451-490.

Cheang MC, Chia SK, Voduc D, Gao D, Leung S, Snider J, Watson M, Davies S, Bernard PS, Parker JS, Perou CM, Ellis MJ, Nielsen TO (2009) Ki67 index, HER2 status, and prognosis of patients with luminal B breast cancer. J Natl Cancer Inst 101: 736-750.

Cornfield DB, Palazzo JP, Schwartz GF, Goonewardene SA, Kovatich AJ, Chervoneva I, Hyslop T, Schwarting R (2004) The prognostic significance of multiple morphologic features and biologic markers in ductal carcinoma in situ of the breast: a study of a large cohort of patients treated with surgery alone. Cancer 100: 2317-2327.

Correa C, McGale P, Taylor C, Wang Y, Clarke M, Davies C, Peto R, Bijker N, Solin L, Darby S (2010) Overview of the randomized trials of radiotherapy in ductal carcinoma in situ of the breast. J Natl Cancer Inst Monogr 2010: $162-177$.

Cuzick J (2003) Aromatase inhibitors in prevention-data from the ATAC (arimidex, tamoxifen alone or in combination) trial and the design of IBIS-II (the second International Breast Cancer Intervention Study). Recent results. Cancer Res 163: 96-103.

Cuzick J, Sestak I, Pinder SE, Ellis IO, Forsyth S, Bundred NJ, Forbes JF, Bishop H, Fentiman IS, George WD (2011) Effect of tamoxifen and radiotherapy in women with locally excised ductal carcinoma in situ: longterm results from the UK/ANZ DCIS trial. Lancet Oncol 12: 21-29.

Decensi A, Gandini S, Serrano D, Cazzaniga M, Pizzamiglio M, Maffini F, Pelosi G, Daldoss C, Omodei U, Johansson H, Macis D, Lazzeroni M, Penotti M, Sironi L, Moroni S, Bianco V, Rondanina G, Gjerde J, Guerrieri-Gonzaga A, Bonanni B (2007) Randomized dose-ranging trial of tamoxifen at low doses in hormone replacement therapy users. J Clin Oncol 25: 4201-4209.

Decensi A, Pruneri G, Guerrieri-Gonzaga A (2012) Estrogen receptor in breast ductal carcinoma in situ: good cop, bad cop? J Clin Oncol 30: 1384-1386.
Decensi A, Robertson C, Viale G, Pigatto F, Johansson H, Kisanga ER, Veronesi P, Torrisi R, Cazzaniga M, Mora S, Sandri MT, Pelosi G, Luini A, Goldhirsch A, Lien EA, Veronesi U (2003) A randomized trial of low-dose tamoxifen on breast cancer proliferation and blood estrogenic biomarkers. J Natl Cancer Inst 95: 779-790.

De Placido S, De Laurentiis M, Carlomagno C, Gallo C, Perrone F, Pepe S, Ruggiero A, Marinelli A, Pagliarulo C, Panico L, Pettinato G, Petrella G, Bianco AR (2003) Twenty-year results of the Naples GUN randomized trial: predictive factors of adjuvant tamoxifen efficacy in early breast cancer. Clin Cancer Res 9: 1039-1046.

Dowsett M, Nielsen TO, A'Hern R, Bartlett J, Coombes RC, Cuzick J, Ellis M, Henry NL, Hugh JC, Lively T, McShane L, Paik S, Penault-Llorca F, Prudkin L, Regan M, Salter J, Sotiriou C, Smith IE, Viale G, Zujewski JA, Hayes DF (2011) Assessment of Ki67 in breast cancer: recommendations from the International Ki67 in Breast Cancer Working Group. J Natl Cancer Inst 103: 1656-1664.

Dowsett M, Smith IE, Ebbs SR, Dixon JM, Skene A, A'Hern R, Salter J, Detre S, Hills M, Walsh G (2007) Prognostic value of Ki67 expression after short-term presurgical endocrine therapy for primary breast cancer. J Natl Cancer Inst 99: 167-170.

Durrleman S, Simon R (1989) Flexible regression models with cubic splines. Stat Med 8: 551-561.

Ellis MJ, Tao Y, Luo J, A'Hern R, Evans DB, Bhatnagar AS, Chaudri Ross HA, von KA, Miller WR, Smith I, Eiermann W, Dowsett M (2008) Outcome prediction for estrogen receptor-positive breast cancer based on postneoadjuvant endocrine therapy tumor characteristics. J Natl Cancer Inst 100: $1380-1388$.

Fisher B, Dignam J, Wolmark N, Mamounas E, Costantino J, Poller W, Fisher ER, Wickerham DL, Deutsch M, Margolese R, Dimitrov N, Kavanah M (1998) Lumpectomy and radiation therapy for the treatment of intraductal breast cancer: findings from National Surgical Adjuvant Breast and Bowel Project B-17. J Clin Oncol 16: 441-452.

Fisher B, Dignam J, Wolmark N, Wickerham DL, Fisher ER, Mamounas E, Smith R, Begovic M, Dimitrov NV, Margolese RG, Kardinal CG, Kavanah MT, Fehrenbacher L, Oishi RH (1999) Tamoxifen in treatment of intraductal breast cancer: National Surgical Adjuvant Breast and Bowel Project B-24 randomised controlled trial. Lancet 353: 1993-2000.

Fisher B, Land S, Mamounas E, Dignam J, Fisher ER, Wolmark N (2001) Prevention of invasive breast cancer in women with ductal carcinoma in situ: an update of the national surgical adjuvant breast and bowel project experience. Semin Oncol 28: 400-418.

Goldhirsch A, Ingle JN, Gelber RD, Coates AS, Thurlimann B, Senn HJ (2009) Thresholds for therapies: highlights of the St Gallen International Expert Consensus on the primary therapy of early breast cancer 2009. Ann Oncol 20: 1319-1329.

Goldhirsch A, Wood WC, Coates AS, Gelber RD, Thurlimann B, Senn HJ (2011) Strategies for subtypes-dealing with the diversity of breast cancer: highlights of the St. Gallen International Expert Consensus on the Primary Therapy of Early Breast Cancer 2011. Ann Oncol 22: 1736-1747.

Guerrieri-Gonzaga A, Botteri E, Lazzeroni M, Rotmensz N, Goldhirsch A, Varricchio C, Serrano D, Cazzaniga M, Bassi F, Luini A, Bagnardi V, Viale G, Mora S, Bollani G, Albertazzi E, Bonanni B, Decensi A (2010) Low-dose tamoxifen in the treatment of breast ductal intraepithelial neoplasia: results of a large observational study. Ann Oncol 21: 949-954.

Guerrieri-Gonzaga A, Robertson C, Bonanni B, Serrano D, Cazzaniga M, Mora S, Gulisano M, Johansson H, Intra M, Latronico A, Franchi D, Pelosi G, Johnson K, Decensi A (2006) Preliminary results on safety and activity of a randomized, double-blind, $2 \times 2$ trial of low-dose tamoxifen and fenretinide for breast cancer prevention in premenopausal women. J Clin Oncol 24: 129-135.

Houghton J, George WD, Cuzick J, Duggan C, Fentiman IS, Spittle M (2003) Radiotherapy and tamoxifen in women with completely excised ductal carcinoma in situ of the breast in the UK, Australia, and New Zealand: randomised controlled trial. Lancet 362: 95-102.

Kerlikowske K, Molinaro A, Cha I, Ljung BM, Ernster VL, Stewart K, Chew K, Moore DH, Waldman F (2003) Characteristics associated with recurrence among women with ductal carcinoma in situ treated by lumpectomy. J Natl Cancer Inst 95: 1692-1702.

Kerlikowske K, Molinaro AM, Gauthier ML, Berman HK, Waldman F, Bennington J, Sanchez H, Jimenez C, Stewart K, Chew K, Ljung BM, Tlsty TD (2010) Biomarker expression and risk of subsequent tumors after initial ductal carcinoma in situ diagnosis. J Natl Cancer Inst 102: 627-637. 
Lari SA, Kuerer HM (2011) Biological markers in DCIS and risk of breast recurrence: a systematic review. J Cancer 2: 232-261.

Latta EK, Tjan S, Parkes RK, O'Malley FP (2002) The role of HER2/neu overexpression/amplification in the progression of ductal carcinoma in situ to invasive carcinoma of the breast. Mod Pathol 15: 1318-1325.

McShane LM, Altman DG, Sauerbrei W, Taube SE, Gion M, Clark GM (2006) REporting recommendations for tumor MARKer prognostic studies (REMARK). Breast Cancer Res Treat 100: 229-235.

NSABP-B-35 (2012). A clinical trial to compare anastrozole and tamoxifen for postmenopausal patients with ductal carcinoma in situ undergoing lumpectomy with radiation therapy. http://clinicaltrials.gov/ct2/show/ NCT00053898?term=B-35\&rank=1.

Osborne CK, Bardou V, Hopp TA, Chamness GC, Hilsenbeck SG, Fuqua SA, Wong J, Allred DC, Clark GM, Schiff R (2003) Role of the estrogen receptor coactivator AIB1 (SRC-3) and HER-2/neu in tamoxifen resistance in breast cancer. J Natl Cancer Inst 95: 353-361.

Paszat LF, Mackillop WJ, Groome PA, Boyd C, Schulze K, Holowaty E (1998) Mortality from myocardial infarction after adjuvant radiotherapy for breast cancer in the surveillance, epidemiology, and end-results cancer registries. J Clin Oncol 16: 2625-2631.

Paszat LF, Vallis KA, Benk VM, Groome PA, Mackillop WJ, Wielgosz A (2007) A population-based case-cohort study of the risk of myocardial infarction following radiation therapy for breast cancer. Radiother Oncol 82: 294-300.

Provenzano E, Hopper JL, Giles GG, Marr G, Venter DJ, Armes JE (2003) Biological markers that predict clinical recurrence in ductal carcinoma in situ of the breast. Eur J Cancer 39: 622-630.

Rakovitch E, Nofech-Mozes S, Hanna W, Narod S, Thiruchelvam D, Saskin R, Spayne J, Taylor C, Paszat L (2012) HER2/neu and Ki-67 expression predict non-invasive recurrence following breast-conserving therapy for ductal carcinoma in situ. Br J Cancer 106: 1160-1165.

Ringberg A, Anagnostaki L, Anderson H, Idvall I, Ferno M (2001) Cell biological factors in ductal carcinoma in situ (DCIS) of the breastrelationship to ipsilateral local recurrence and histopathological characteristics. Eur J Cancer 37: 1514-1522.

Royston P, Sauerbrei W (2004) A new approach to modelling interactions between treatment and continuous covariates in clinical trials by using fractional polynomials. Stat Med 23: 2509-2525.

Rudloff U, Jacks LM, Goldberg JI, Wynveen CA, Brogi E, Patil S, Van Zee KJ (2010) Nomogram for predicting the risk of local recurrence after breast-conserving surgery for ductal carcinoma in situ. J Clin Oncol 28: 3762-3769.

Solin LJ (2012) Selecting individualized treatment for patients with ductal carcinoma in situ of the breast: the search continues. J Clin Oncol 30: 577-579.

Tavassoli FA (1998) Ductal carcinoma in situ: introduction of the concept of ductal intraepithelial neoplasia. Mod Pathol 11: 140-154.

Tavassoli FA (2005) Breast pathology: rationale for adopting the ductal intraepithelial neoplasia (DIN) classification. Nat Clin Pract Oncol 2: 116-117.
Thorpe SM, Christensen IJ, Rasmussen BB, Rose C (1993) Short recurrencefree survival associated with high oestrogen receptor levels in the natural history of postmenopausal, primary breast cancer. Eur J Cancer 29A: 971-977.

Urruticoechea A, Smith IE, Dowsett M (2005) Proliferation marker Ki-67 in early breast cancer. J Clin Oncol 23: 7212-7220.

Veronesi U, Viale G, Rotmensz N, Goldhirsch A (2006) Rethinking TNM: breast cancer TNM classification for treatment decision-making and research. Breast 15: 3-8.

Viale G, Regan MM, Maiorano E, Mastropasqua MG, Dell'Orto P, Rasmussen BB, Raffoul J, Neven P, Orosz Z, Braye S, Ohlschlegel C, Thurlimann B, Gelber RD, Castiglione-Gertsch M, Price KN, Goldhirsch A, Gusterson BA, Coates AS (2007) Prognostic and predictive value of centrally reviewed expression of estrogen and progesterone receptors in a randomized trial comparing letrozole and tamoxifen adjuvant therapy for postmenopausal early breast cancer: BIG 1-98. $J$ Clin Oncol 25: 3846-3852.

Vicini FA, Kestin LL, Goldstein NS, Chen PY, Pettinga J, Frazier RC, Martinez AA (2000) Impact of young age on outcome in patients with ductal carcinoma-in-situ treated with breast-conserving therapy. J Clin Oncol 18: 296-306.

Wang SY, Shamliyan T, Virnig BA, Kane R (2011) Tumor characteristics as predictors of local recurrence after treatment of ductal carcinoma in situ: a meta-analysis. Breast Cancer Res Treat 127: 1-14.

Wapnir IL, Dignam JJ, Fisher B, Mamounas EP, Anderson SJ, Julian TB, Land SR, Margolese RG, Swain SM, Costantino JP, Wolmark N (2011) Long-term outcomes of invasive ipsilateral breast tumor recurrences after lumpectomy in NSABP B-17 and B-24 randomized clinical trials for DCIS. J Natl Cancer Inst 103: 478-488.

Yi M, Meric-Bernstam F, Kuerer HM, Mittendorf EA, Bedrosian I, Lucci A, Hwang RF, Crow JR, Luo S, Hunt KK (2012) Evaluation of a breast cancer nomogram for predicting risk of ipsilateral breast tumor recurrences in patients with ductal carcinoma in situ after local excision. J Clin Oncol 30: 600-607.

Zanardi S, Branchi D, Ponti A, Cruciani G, D'Amico C, Cortesi L, Falcini F, Gulisano M, Giardina G, Canavese G, Calabrese M, Decensi A, Puntoni M, Campora S, Argusti A, Bonanni B, Guerrieri-Gonzaga A, Johansson H, Paquola MG, D’Aiuto G (2011) Randomized, placebo controlled, phase III trial of low-dose tamoxifen in women with intraepithelial neoplasia (abstract)]. In: Proceedings of the Tenth Annual Meeting of the AACR International Conference on Frontiers in Cancer Prevention Research, 22-25 October, Boston, MA, USA. Abstract no. A56, 73. 2011.

This work is published under the standard license to publish agreement. After 12 months the work will become freely available and the license terms will switch to a Creative Commons AttributionNonCommercial-Share Alike 3.0 Unported License. 